\title{
ACEII gene analysis exposes SARS-CoV-2 as a potential threat to agricultural and national security.
}

Authors: Ruhl, Michael W. ${ }^{1 *}$, Jenkins, Tracie M. ${ }^{2 \dagger}$

Affiliations:

${ }^{1}$ Grand Canyon University, College of Doctoral Studies, Phoenix, AZ 85017, USA

${ }^{2}$ University of Georgia, Department of Entomology, Athens, GA 30602, USA.

*Correspondence to mruhl@ my.gcu.edu.

$\dagger$ Professor Emerita.

\section{Key Words:}

Food safety, SARS-CoV-2, coronavirus, ACEII, agricultural security, national security.

\begin{abstract}
Coronavirus is now a significant human pathogen with the emergence of SARS-CoV-2. Until now there has been no data to support a threat to agricultural industries. Using a comparative genomic protein analysis, this study examined the angiotensin-converting enzyme II (ACEII) gene of 17 animal species with an emphasis on agriculture. To determine viral vulnerability the 20 known SARS-CoV-2 receptor-binding domain (RBD)/ACEII receptor interaction sites were compared to determine their potential susceptibility to the SARS-CoV-2 virus. With the known bat host's (XP_032963186) number of binding sites as a threshold, we note that ALL animal species examined in this study contained significant numbers $(\geq 10)$ of SARS-CoV-2 binding sites and could be at risk for SARS-CoV-2 infection. The data from this study suggest SARS-CoV-2 imposes a grave threat to the safety and security of the agricultural industry. Urgent studies are needed to determine if infected animals can transmit SARS-CoV-2 before and/or after processing.

\section{Introduction}

Until recently it was unknown whether animals could become infected by SARS-CoV-2. Despite the widespread suspicion that SARS-CoV-2 originated from a bat (RaTG13| MN996532.1), it remains unclear whether other animal species may be viable primary or
\end{abstract}


secondary hosts. Preliminary data (Chen et al. 2020) suggest various animal groups contain SARS-CoV-2 interaction sites between the SARS-CoV-2 spike protein receptor-binding domain (RBD) and the angiotensin-converting enzyme II (ACEII) gene. This RBD has 16 amino acid residues capable of interacting with 20 ACEII amino acid sites (Li et al. 2005, Chen et al. 2020).

Since the onset of the SARS-CoV-2 pandemic, we have identified and verified that tigers (Gollakner and Capua 2020, Mahdy 2020) and lions serve as SARS-CoV-2 hosts. To determine if SARS-CoV-2 poses a potential threat to agricultural and national security this study examines the SARS-CoV-2 spike protein RBD sites that are capable of interacting with the ACEII gene of 17 animals identified as having agricultural significance.

\section{Materials and Methods}

Human and animal ACEII gene sequences (Table 1) were queried on the NCBI gene database (Anjay 2012) and compiled to fasta format using Notepad++ (Ho 2020). The resulting fasta file of ACEII protein sequences was aligned using Muscle (Edgar 2004a, 2004b) with the default algorithm and parameters within UGENE v34 (Okonechnikov et al. 2012). A second alignment was performed using the Cobalt tool within the NCBI site (Papadopoulos and Agarwala 2007). The second alignment was necessary as UGENE lacks a nexus file format option when exporting alignments.

Using UGENE a distance matrix was generated using the following parameters: Distance algorithm $=$ Similarity, Profile mode $=$ Percentage, Save profile to file $=$ checked, File $=$ Commaseparated (.CSV). The human reference sequence must be in the first position when generating a distance matrix. The distance matrix generation process was repeated after removing all amino acid residues other than the 20 known ACEII interactive sites.

Using ACEII gene alignment, all sequences were examined for SARS-CoV-2/ACEII gene interaction sites using the 20 known human sites as the reference (Li et al. 2005, Chen et al. 2020). Amino acid changes were annotated and represented graphically using both MSWord and SnagIt Editor (Bragg 2002). The number of matching amino acid residue sites were denoted into a spreadsheet and exported as for visualization.

Using human (NP_001358344) reference sequence, amino acids that differ from human SARS-CoV-2 interaction sites were queried manually and recorded in table format. The similarity value obtained from the lowest scoring known host was used as a threshold value to determine the possibility of COVID-19 infection. 


\section{Results}

Amino acid alignment of the ACEII binding domain (Appendix 1) reveals a highly homologous binding domain between species. Most SARS-CoV-2/ACE II interactive sites in this binding domain lie within the $\alpha$-helices and $\beta$-sheets of the ACEII complex structure.

The similarity distance matrix demonstrates that the human ACEII gene shares $\geq 78 \%$ whole gene identity to all species in this study except the 4 birds; emu $65 \%$, turkey $55 \%$, chicken $66 \%$, and pheasant $66 \%$ (Appendix 2a-c). When only the 20 ACEII interaction sites are analyzed, all species except the 4 birds; emu 53\%, turkey 58\%, chicken 58\%, and pheasant 58\%, in addition to bat (55\%) demonstrate $\geq 75 \%$ similarity (Appendix 3a-c).

Our study noted the following AA residue differences in the hydrophobic pockets created by F28, L79, Y83, and L97: Birds p.L79N, Pig p.L79I, and all others except donkey and horse p.L79M; birds and bat p.Y83F; and birds p.L97I in birds (Appendix 1). F28 was conserved in all species.

The known host species with the least number of SARS-CoV-2/ACEII complex structure interaction sites were identified as being horseshoe bat (XP_032963186) with 10 interaction sites. The known host tiger, as well as cattle, sheep, goat, bison, and deer, contained the most SARS-CoV-2 interaction sites outside of humans (Table 2).

Table 2. SARS-CoV-2/ACEII amino acid (AA) residue interaction sites. Known SARS-CoV-2 hosts are denoted with a black background.

\begin{tabular}{|l|c|}
\hline Accession number|Common name & $\begin{array}{c}\text { Amino acid } \\
\text { interactions }\end{array}$ \\
\hline XP_005228485|Cattle & 17 \\
\hline XP_027389727|Hybrid cattle X1 & 17 \\
\hline XP_027389729|Hybrid CattleX2 & 17 \\
\hline NP_001116542|Pig & 15 \\
\hline XP_011961657|Domestic sheep & 17 \\
\hline NP_001277036|Domestic goat & 17 \\
\hline XP_025976569|Emu & 10 \\
\hline XP_001490241|Horse & 15 \\
\hline XP_014713133|Donkey & 15 \\
\hline XP_006212709|Alpaca & 15 \\
\hline XP_416822|Chicken & 10 \\
\hline XP_019467554|Turkey & 10 \\
\hline XP_010833001|American bison & 17 \\
\hline
\end{tabular}




\begin{tabular}{|l|l|} 
XP_020768965|Texas whitetail deer & 17 \\
\hline XP_031451919|Common pheasant & 10 \\
\hline NP_001358344|Human & $\mathbf{2 0}$ \\
XP_007090142|Tiger & $\mathbf{1 7}$ \\
XP_032963186|Horseshoe bat & $\mathbf{1 0}$ \\
\hline
\end{tabular}

Species with the greatest number of SARS-CoV-2 interaction sites contained 17; including cattle, sheep, goat, bison, deer, and tiger. Donkey, horse, and alpaca have 15 binding sites.

\section{Discussion}

$\underline{\text { Structural analysis }}$

It has been previously described that the unique SARS-CoV-2 F486 site is capable of binding deep in the ACEII hydrophobic pockets created by F28, L79, Y83, and L97 (Chen et al. 2020). The interspecies AA residue differences of those sites, noted in this study, conserve the hydrophobic pockets in the ACEII complex structure by use of other hydrophobic residue substitutions. Of note is the p.Y83F substitution in birds and bats which creates $\pi$-stacking of aromatic residues (McGaughey et al. 1998), an effect that can alter drug effectiveness/design (Graci and Cameron 2008). It also creates a disulfide bond with F486 increasing virus binding affinity ( $k=6)(C h e n$ et al. 2007). This improved binding affinity may alter our AA interaction threshold estimate, 10 in known host bat, for establishing infection in a host. It is conceivable that these species with p.Y83F would not require as many sites to cause infection since they could theoretically acquire similar virus-host bonding strengths with less interacting residues.

Other than birds, all animals in this study contained at least 15 SARS-CoV-2/ACEII complex structure interaction sites. This number of interaction sites is well above our threshold value established by the know bat host at 10 . This may or may not be cause for concern but it certainly leads to a high index suspicion of their SARS-CoV-2 host viability. $\underline{\text { Historical coronavirus evidence in agricultural species }}$

It is important to understand that ALL species in this study have been previously identified as a host for a coronavirus; cattle (Weiyan and Chengping 1990), chicken, pheasant (Culver et al. 2008), turkey (Guy et al. 1997), pig (Woo et al. 2017), sheep (Tråvén et al. 1999), goat, bison (Weiyan and Chengping 1990), emu (Kummrow 2015), donkey, horse, (Nagano 1982, OUE et al. 2013, Fielding et al. 2015), alpaca (Jin et al. 2007, Crossley et al. 2012), bison (Amer 2019, Harms et al. 2019), and deer (Amer 2019). While not SARS-CoV-2, they were of 
the same closely related viral coronavirus genus. The possibility to host SARS-CoV-2 should not be disregarded until experimentally proven otherwise.

It is still not known what the pathogenic effect, if any, will be in SARS-CoV-2 infected animals. Looking at historical data from bovine coronavirus (BCoV) infections (Boileau and Kapil 2010), it is conceivable that SARS-CoV-2 could have serious implications in the morbidity and mortality of cattle < 2years old.

$\underline{\text { SARS-CoV-2 agricultural and national security risk }}$

SARS-CoV-2 has demonstrated surface survivability of up to 9 days (Kampf et al. 2020). Coronavirus in excreted body fluids can survive $>7$ days (Lai et al. 2005). Our understanding is that survivability in biological tissues has yet to be determined but from excreted fluids, we can infer survivability of the virus is also $>7$ days. Within biological tissues the virus' survivability could increase beyond 20 days when refrigerated (Guionie et al. 2013), a vital process to avert food spoilage. A commonly used method to increase food preservation is gamma irradiation (Diehl 2002, Piri et al. 2011). This process may not inactivate enough of the virus to prevent viral transmission as demonstrated by gamma irradiation studies with the Ebola virus (Hume et al. 2016). In that study, it was determined that "no dosage could be considered to inactivate 100\% of a sample" (Hume et al. 2016). Principally, viral transmission was possible after gamma irradiation.

Infected animals and humans may also contaminate a water supply if in direct contact. Studies have shown that coronavirus inactivation in water can take over 500 days at $4^{\circ} \mathrm{C}$ or 10 days at $23^{\circ} \mathrm{C}$ (Gundy et al. 2009). This study also indicates the possibility of human to animal spread through an open, contaminated water source such as a water trough. Due to the extreme importance of this viral capacity, the water study should be repeated with SARS-CoV-2 for comparative results.

Until now there has been no data to support a threat to the global food supply. However, existing control measures are not adequate to mitigate SARS-CoV-2 propagation. Food poverty, hunger, and food inequality lead to instability at the local, national, and international levels (Pinstrup-Andersen 2003). These factors highlight the importance of agricultural industries to the security of a nation (Tweeten 1999, Falcon and Naylor 2005, Etim et al. 2017). One needs only to look at recent events in Venezuela for an example of this concept. Preparing and mitigating any potential impact of SARS-CoV-2 on animals is paramount to agricultural and national 
security (Batie and Healy 1980, Winters 1990, HORN and BREEZE 1999, Casagrande 2000). Agricultural industries should begin preparation for a worst-case-scenario before they are forced to respond to one.

Mitigation and control

Coronavirus is now a significant human pathogen with the emergence of SARS-CoV-2. This pathogen has caused severe illness and death in humans and until recently no evidence existed to suggest the agricultural industry was in jeopardy until the recent confirmation of SARS-CoV-2 infections in several Bronx Zoo tigers and lions. To date, it is unknown if the tigers and lions contracted the disease through human interaction, another intermediate vector, or a contaminated food source. If by an alternative vector or food/water-borne mode of spread, it poses significant challenges to the control of agricultural disease propagation.

Currently, social isolation, respiratory barrier masks, and personal sanitation measures are the only available forms of SARS-CoV-2 mitigation. This is not a possibility for agricultural industry animals where animals are typically kept in large numbers and close proximity to each other. As a result, the risk of one animal infecting another would appear to be extremely high. Even with free-range animals, their natural herd tendencies sustain a viral transmission risk. While numerous studies have shown that viruses can spread quickly with a high degree of population penetrance, no studies are found to document coronavirus transmission to humans or other animals through food/water consumption or handling during processing. The absence of this data does not eliminate this prospect. The rate of raw meat processing plant worker infections is alarming and should raise concern as to the root source of spread since this phenomena is not observed in other industries of similar scale.

While the ACEII gene is highly conserved between species, this study was limited by using the human ACEII gene sequence as a reference. Actual SARS-CoV-2/ACEII animal complex structure interactions could differ in animals. Another limitation of this study was that SARS-CoV-2 survivability in tissues and water must be inferred from other human coronaviruses. SARS-CoV-2 survivability in these media may differ under identical environmental conditions. Lack of animal testing precludes a definitive viral susceptibility analysis. Our work establishes the framework for a SARS-CoV-2 infection risk amongst animals. Future studies should test living and processed animal samples to determine primary and secondary host viability. 


\section{$\underline{\text { Summary }}$}

Using a comparative genomic protein analysis this study found that all animal species in this study contained significant numbers of SARS-CoV-2/ACEII complex structure interaction sites and could be considered at risk for SARS-CoV-2 infection. Data from this study suggest SARS-CoV-2 imposes a grave threat to agricultural and national security. Urgent studies are needed to determine if infected animals can transmit SARS-CoV-2 before and/or after processing.

Acknowledgments: We gratefully acknowledge the authors, originating and submitting laboratories of the sequences from the NCBI Database on which this research is based. I would like to thank the University of Georgia-Griffin faculty for their valuable guidance in molecular processes. We also recognize the reviewers for their valuable time and insight. Funding: no outside funding sources. Author contributions: Michael Ruhl performed data query, protein analysis, and developed the initial manuscript. Tracie Jenkins was the primary editor and contributed to genomic analysis. Competing interests: Authors have no competing interests to declare. Data and materials availability: all accessions are publicly available and listed in Table 1. All software used is publicly available with citations provided in the manuscript text.

\section{References}

Amer, H. M. 2019. Bovine-like coronaviruses in domestic and wild ruminants. Anim. Heal. Res. Rev. 19: 113-124.

Anjay, A. 2012. National Center for Biotechnology Information (NCBI). Bethesda, Maryland, USA.

Batie, S. S., and R. G. Healy. 1980. Future of American agriculture as a strategic resource.

Boileau, M. J., and S. Kapil. 2010. Bovine Coronavirus Associated Syndromes. Vet. Clin. North Am. - Food Anim. Pract.

Bragg, D. C. 2002. SnaGit, Version 6.1 for Windows. Bull. Ecol. Soc. Am. Vol. 83, No. 4, Oct. 2002 p. $255-256$.

Casagrande, R. 2000. Biological terrorism targeted at agriculture: The threat to US national security. Nonproliferation Rev. 7: 92-105.

Chen, K., L. A. Kurgan, and J. Ruan. 2007. Prediction of flexible/rigid regions from protein sequences using k-spaced amino acid pairs. BMC Struct. Biol. 7: 25.

Chen, Y., Y. Guo, Y. Pan, and Z. J. Zhao. 2020. Structure analysis of the receptor binding of 
2019-nCoV. Biochem. Biophys. Res. Commun. 525: 135-140.

Crossley, B., R. Mock, S. Callison, and S. Hietala. 2012. Identification and Characterization of a Novel Alpaca Respiratory Coronavirus Most Closely Related to the Human Coronavirus 229E. Viruses. 4: 3689-3700.

Culver, F. A., P. Britton, and D. Cavanagh. 2008. RT-PCR detection of avian coronaviruses of galliform birds (Chicken, Turkey, Pheasant) and in a parrot. Methods Mol. Biol. 454: 3542.

Diehl, J. F. 2002. Food irradiation - Past, present and future. Radiat. Phys. Chem. 63: 211-215.

Edgar, R. C. 2004a. MUSCLE: multiple sequence alignment with high accuracy and high throughput. Nucleic Acids Res. 32: 1792-1797.

Edgar, R. C. 2004b. MUSCLE: A multiple sequence alignment method with reduced time and space complexity. BMC Bioinformatics. 5: 113.

Etim, E. E., O. O. Duke, and O. J. O. Jr. 2017. The Implications of Food Insecurity, Poverty and Hunger on Nigeria's National Security. Asian Res. J. Arts Soc. Sci. 1-10.

Falcon, W. P., and R. L. Naylor. 2005. Rethinking Food Security for the Twenty-First Century. Am. J. Agric. Econ. 87: 1113-1127.

Fielding, C. L., J. K. Higgins, J. C. Higgins, S. McIntosh, E. Scott, F. Giannitti, A. Mete, and N. Pusterla. 2015. Disease Associated with Equine Coronavirus Infection and High Case Fatality Rate. J. Vet. Intern. Med. 29: 307-310.

Gollakner, R., and I. Capua. 2020. Is COVID-19 the first pandemic that evolves into a panzootic? Vet. Ital.

Graci, J. D., and C. E. Cameron. 2008. Therapeutically targeting RNA viruses via lethal mutagenesis. Future Virol. 3: 553-566.

Guionie, O., C. Courtillon, C. Allee, S. Maurel, M. Queguiner, and N. Eterradossi. 2013. An experimental study of the survival of turkey coronavirus at room temperature and $+4{ }^{\circ} \mathrm{C}$. Avian Pathol. 42: 248-252.

Gundy, P. M., C. P. Gerba, and I. L. Pepper. 2009. Survival of Coronaviruses in Water and Wastewater. Food Environ. Virol. 1: 10-14.

Guy, J. S., H. J. Barnes, L. G. Smith, and J. Breslin. 1997. Antigenic Characterization of a Turkey Coronavirus Identified in Poult Enteritis- and Mortality Syndrome-Affected Turkeys. Avian Dis. 41: 583. 
Harms, N. J., T. S. Jung, C. L. Andrew, O. P. Surujballi, M. Vanderkop, M. Savic, and T. Powell. 2019. Health status of reintroduced wood bison (Bison bison athabascae): Assessing the conservation value of an isolated population in northwestern Canada. $\mathrm{J}$. Wildl. Dis. 55: 44-53.

Ho, D. 2020. Notepad++, 2020. Retrieved from http//notepad-plus-plus. org.

Horn, F. P., and R. G. Breeze. 1999. Agriculture and Food Security. Ann. N. Y. Acad. Sci. 894: 9-17.

Hume, A. J., J. Ames, L. J. Rennick, W. P. Duprex, A. Marzi, J. Tonkiss, and E. Mühlberger. 2016. Inactivation of RNA viruses by gamma irradiation: A study on mitigating factors. Viruses. 8.

Jin, L., C. K. Cebra, R. J. Baker, D. E. Mattson, S. A. Cohen, D. E. Alvarado, and G. F. Rohrmann. 2007. Analysis of the genome sequence of an alpaca coronavirus. Virology. 365: 198-203.

Kampf, G., D. Todt, S. Pfaender, and E. Steinmann. 2020. Persistence of coronaviruses on inanimate surfaces and their inactivation with biocidal agents. J. Hosp. Infect.

Kummrow, M.S. 2015. Ratites or Struthioniformes, pp. 75-82. In Fowler's Zoo Wild Anim. Med. Vol. 8. Elsevier.

Lai, M. Y. Y., P. K. C. Cheng, and W. W. L. Lim. 2005. Survival of Severe Acute Respiratory Syndrome Coronavirus. Clin. Infect. Dis. 41: e67-e71.

Li, F., W. Li, M. Farzan, and S. C. Harrison. 2005. Structural biology: Structure of SARS coronavirus spike receptor-binding domain complexed with receptor. Science (80-. ). 309: 1864-1868.

Mahdy, M. 2020. An Overview of SARS-CoV-2 and Animal Infection.

McGaughey, G. B., M. Gagné, and A. K. Rappé. 1998. $\pi$-Stacking interactions. Alive and well in proteins. J. Biol. Chem. 273: 15458-15463.

Nagano, S. 1982. Effect of a sterilization locker with ethylene oxide gas. J. Japan Vet. Med. Assoc. 64: 535-539.

Okonechnikov, K., O. Golosova, M. Fursov, and the U. team. 2012. Unipro UGENE: a unified bioinformatics toolkit. Bioinformatics. 28: 1166-1167.

Oue, Y., Y. Morita, T. Kondo, and M. Nemoto. 2013. Epidemic of Equine Coronavirus at Obihiro Racecourse, Hokkaido, Japan in 2012. J. Vet. Med. Sci. 75: 1261-1265. 
Papadopoulos, J. S., and R. Agarwala. 2007. COBALT: constraint-based alignment tool for multiple protein sequences. 23: 1073-1079.

Pinstrup-Andersen, P. 2003. Eradicating Poverty and Hunger as a National Security Issue. Environ. Change Secur. Proj. Rep. 22.

Piri, I., M. Babayan, A. Tavassoli, and M. Javaheri. 2011. The use of gamma irradiation in agriculture. African J. Microbiol. Res. 5: 5806-5811.

Tråvén, M., U. Carlsson, A. Lundén, and B. Larsson. 1999. Serum Antibodies to Bovine Coronavirus in Swedish Sheep. Acta Vet. Scand. 40: 69-74.

Tweeten, L. 1999. The Economics of Global Food Security. Appl. Econ. Perspect. Policy. 21: 473-488.

Weiyan, Y. H. D. N. X., and L. Chengping. 1990. Seroepizootiological Survey Of Bovine Coronavirus In Cattle, Human And Other Animals [J]. J. Nanjing Agric. Univ. 2.

Winters, L. A. 1990. Digging for Victory: Agricultural Policy and National Security. World Econ. 13: 170-191.

Woo, P. C., S. K. Lau, C. C. Tsang, C. C. Lau, P. C. Wong, F. W. Chow, J. Y. Fong, and K. Y. Yuen. 2017. Coronavirus HKU15 in respiratory tract of pigs and first discovery of coronavirus quasispecies in 5'-untranslated region. Emerg. Microbes Infect. 6: e53. 
Table 1. Accession list

\begin{tabular}{l} 
Accession number |common name [scientific name] \\
\hline NP_001358344|Human [Homo sapiens] \\
\hline XP_005228485|Cattle [Bos taurus] \\
\hline XP_027389727|Hybrid cattleX1 [Bos indicus X Bos taurus] \\
\hline XP_027389729|Hybrid cattleX2 [Bos indicus X Bos taurus] \\
\hline NP_001116542|Pig [Sus scrofa] \\
\hline XP_011961657|Domestic sheep [Ovis aries] \\
\hline NP_001277036|Domestic goat [Capra hircus] \\
\hline XP_025976569|Emu [Dromaius novaehollandiae] \\
\hline XP_001490241|Horse [Equus caballus] \\
\hline XP_014713133|Donkey [Equus asinus] \\
\hline XP_006212709|Alpaca [Vicugna pacos] \\
\hline XP_416822|Chicken [Gallus gallus] \\
\hline XP_019467554|Turkey [Meleagris gallopavo] \\
\hline XP_010833001|American bison [Bison bison bison] \\
\hline XP_020768965|Texas whitetail deer [Odocoileus virginianus texanus] \\
\hline XP_031451919|Common pheasant [Phasianus colchicus] \\
\hline XP_007090142|Tiger [Panthera tigris altaica] \\
\hline XP_032963186.1|Horseshoe bat [Rhinolophus ferrumequinum] \\
\hline
\end{tabular}




\section{Appendices}

Appendix 1. ACEII protein sequence alignment (1a, 1b, 1c, and 1d). Only regions containing SARS-CoV-2 interaction sites are shown. Bold white letters with black background indicate the similarity of SARS-CoV-2 interaction sites to the human ACEII reference sequence. Clear boxes denote alpha-helices, shaded boxes denote $\beta$-sheets. Conserved interactive amino acid residues are seen at F28, E37, L45, N331, K354, D356, and R358.

$1 a$.

\begin{tabular}{|c|c|c|c|c|}
\hline \multicolumn{5}{|l|}{ FERENC } \\
\hline Cattle & 28 & TIEEOQAKIFLEKFMM EAEDLSYQSS & SLASWNYNTINITDENVQKMNEARAKW & \\
\hline Hybrid cattle $x_{1}$ & 20 & EQAKTFI & LASWNYNTINIT EENVQKMNEARAKW & \\
\hline ybrid cattle $\times 2$ & 20 & EEQAKIFL & SL LSWNYNTNITDENVQKMNEARAKW & \\
\hline ig & 20 & TEELAKTFLEX KFNLEAEDLAYCO & SLASWT INTNITDENIQKMNDARAKW & \\
\hline mestic sheep & 20 & TEGQAKIFLEXFNAEAEDLSYCSS & SS 1 ASWNYNTNIT DENVQKMNEARAKW & \\
\hline Domestic goat & 28 & EQAKTFL & SLASWNYNTNITDENVQKMNEARAKW & \\
\hline Emu & 20 & $\sqrt{T E-Q A Q I F L T E F N I K A E D I S \overline{Y E}}$ & SI LASWNYNTNIT EET SMKMNEADAKW & \\
\hline 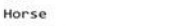 & & DLAKTFI & ITDENVQKMNEAGARW & \\
\hline onkey & 20 & TrEDLAKIFLEXFNSEAEELLFOSS & SLLSWSYNTINITDENVQKMNEAGARW & \\
\hline lpa & 20 & TTEELAKTFLKEFNHEAEDRSYC: & SL LSWNYNTINITDENVQKMNDARAKW & \\
\hline iic & 2 & Q-EACIF & TEETARKMSEAGAKW & \\
\hline urkey & 2 & $\sqrt{\text { TQ-EACTFLAEFNVRAEDTSVEN }}$ & ISLASWDYNTNIT TEETARKMSEAGAKW & \\
\hline bison & 28 & KFNAEAEDLSYQ & DENVQKMNEARAKW & \\
\hline itetail & 2 & EQAKIFL & WASWNYNTINITENVQKMNEARAKW & \\
\hline Common & 28 & $\sqrt{T Q-E A Q T F L A E F N A R A E D I}$ & ISLASWDYNTNITEETARKMSEAGTKW & \\
\hline Huma & 20 & 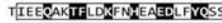 & SLASWNYNTNIT EENVQNMNNAGDKW & \\
\hline & & AKIF & LASWWYNTINITEENVQKMNEAGAKW & \\
\hline Hors & 20 & EDLAK & SDENVQKMDEAC & \\
\hline
\end{tabular}

$1 c$.

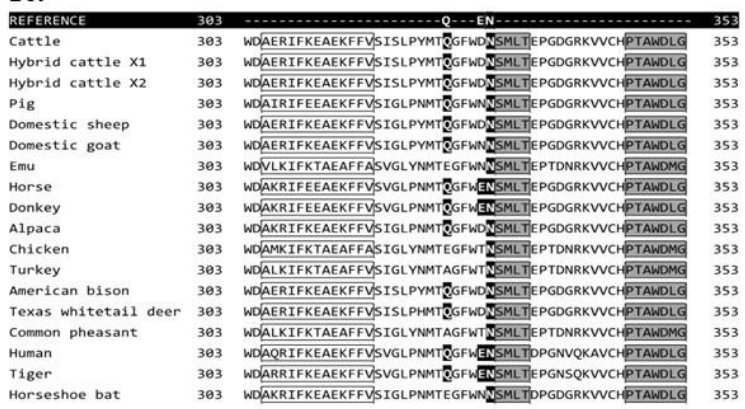

$1 b$.

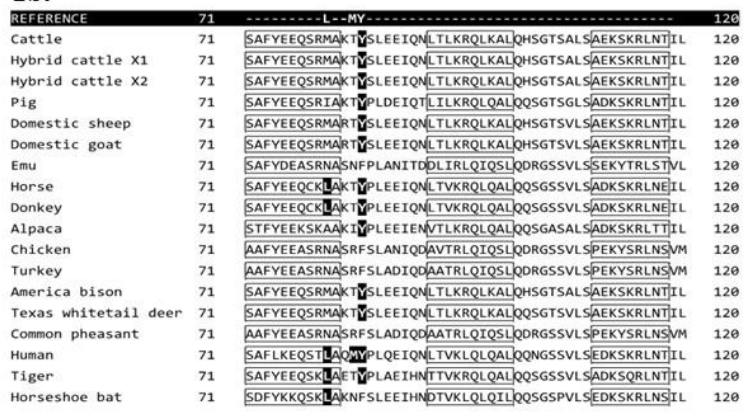

$1 d$.

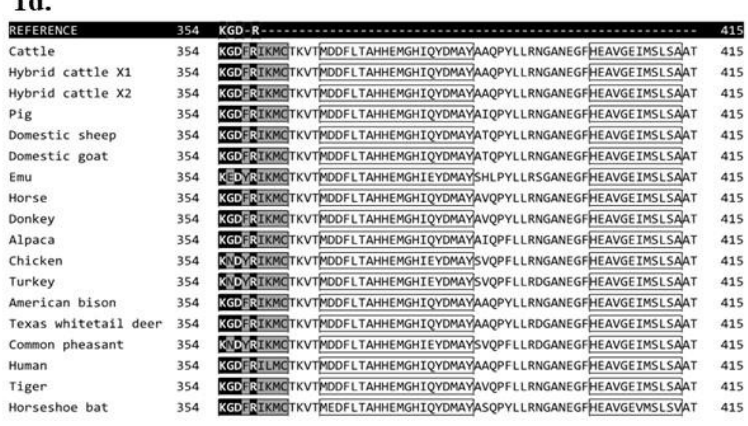


Appendix 2. Distance matrix table comparing ACEII sequences (2a: humans, cattle, pigs, and sheep; $2 \mathrm{~b}$ : goat, emu, horse, donkey, alpaca, and chicken; 2c: turkey, bison, deer, pheasant, tiger, and bat).

\begin{tabular}{|c|c|c|c|c|c|c|}
\hline 22. & Human & Cattle & $\begin{array}{l}\text { Mybrid } \\
\text { cattle } \times 1\end{array}$ & $\begin{array}{l}\text { Mybrid } \\
\text { cattle } \times 2\end{array}$ & Pis & Sheep. \\
\hline NP_Co1358344Human [Home sapicas] & 1005 & $78 \% 6$ & $78 \%$ & $81 \%$ & $81 \%$ & 825 \\
\hline XP $\cos 228485$ Canle [Bes taurus] & $78 \% 6$ & $100 \%$ & $99 \%$ & $95 \%$ & $84 \%$ & $92 \%$ \\
\hline $\mathrm{Xr}$ 027389727Hybrid camle XI [Bos indicus $\mathrm{x}$ Bos tarirus] & $78 \%$ & $99 \%$ & $100 \%$ & $95 \%$ & $84 \%$ & $93 \%$ \\
\hline XP 027389729Hybrid cattle X2 [Bos indicus $\times$ Bos taurus] & $81 \%$ & $96 \%$ & $96 \%$ & $100 \%$ & $88 \%$ & $97 \%$ \\
\hline NP_.001116542Pie [Ses scroda] & $81 \%$ & $84 \%$ & $84 \%$ & $88: 6$ & 100 s & 878 \\
\hline XP ol1961657 Domestic shes? [Ovis aries] & $82 * 6$ & $93 \%$ & $93 \%$ & $97 \%$ & $88 \%$ & $100 \%$ \\
\hline NF_001277036.Domestic pout [Capra hircus] & $82 \%$ & $94 \%$ & $94 \%$ & $98 \%$ & $88 \%$ & 9es. \\
\hline XP 025976569 Fmu [Dromaius novachollandiae] & $65 \%$ & $65 \%$ & $65 \%$ & $66 \%$ & $66 \%$ & 605 \\
\hline Xr Col490241 Horse [Equus caballus] & 8726 & $82 \%$ & 824 & 855 & $87 \%$ & $x 5 \%$ \\
\hline XP 014713133 Donkey [Equus asimus] & $86 \%$ & $81 \%$ & $81 \%$ & $84 \%$ & $86 \%$ & $x 45$ \\
\hline XP_Co6212709 Alpaca [Visugas pacos] & $83 \%$ & $80 \%$ & $84 \%$ & $88 \% 6$ & $90 \%$ & ks:5 \\
\hline XP 416822 Chicken [Gallus gallus] & $66 \%$ & $64 \%$ & $64 \%$ & $65 \%$ & 665 & $66 \%$ \\
\hline Xr o19467554 Turkey [Meleagris gallopavo] & $55 \%$ & $55 \%$ & $55 \%$ & $55 \%$ & 55: & $56 \%$ \\
\hline XP. otcos33001 American bisen [Bison bison bisoed] & $81 \%$ & $100 \%$ & $100 \%$ & $100 \%$ & $89 \%$ & $98 \%$ \\
\hline XP 020765965 Teras whitetail dect [Odocoskeus virginianus texanus] & $78 \%$ & $92 \%$ & $92 \div 6$ & 9256 & $85: 5$ & 925 \\
\hline XP_031451919 Comunon phrasam [Phasianus colkticus] & $66 \%$ & $65 \%$ & $65 \%$ & $66 \%$ & 665 & 665 \\
\hline XP_co7090142/Tiger [Pantbera tigris altaica] & $86 \%$ & $80 \%$ & 8006 & $83 \%$ & $83 \%$ & 834 \\
\hline XP_032963186,1 Honcehus bat [Rhinolophas fernunsegiaum] & $81 \%$ & $77 \%$ & $77 \%$ & $80 \%$ & $80 \mathrm{~s}$ & 80: \\
\hline 20 & Goat & Emu: & Hotse & Donkey & Alpaca & Chicken \\
\hline NF_0013583463luman [Homo sapisna]. & $82 \%$ & $65 \%$ & $87 \%$ & 834 & $83 \%$ & 605 \\
\hline XP 005228485 Canle [Bos taurus] & 935 & $64 \%$ & $82 \%$ & $78 \%$ & B4\% & 645 \\
\hline XP 027389727Hybrid cattk X1 [Bos indicus $\times$ Bos tancus] & $93 \%$ & $64 \%$ & $82 \%$ & $7 \times 6$ & $24 \%$ & $64 \%$ \\
\hline XP 027389729 Hybrid carte X2 [Bos indicus $\times$ Bos tarue] & 985 & $66 \%$ & $86 \%$ & $82 \%$ & $88 \%$ & 665 \\
\hline NP_001116542 Piv [Sas scrota] & 885 & $66 \%$ & $87 \%$ & 834 & $90 \%$ & $66 \%$ \\
\hline XP 01 1961657 Domestic sbeep [Ovis aries] & 99s: & $66 \%$ & $86 \%$ & $82 \%$ & $88 \%$ & $66 \%$ \\
\hline NP. 001277036 Dornestic gout [Capra lítcus] & $100 \%$ & $66 \%$ & $85 \%$ & $82 \%$ & $88 \% 6$ & $66 \%$ \\
\hline XP 023976569:mu [Dremaius novachollandiac] & $66 \%$ & $100 \%$ & $67 \%$ & $65 \%$ & $66 \%$ & 845 \\
\hline XP_001490241Honse (Fquas caballed & $85 \%$ & 6766 & 1005 & 96: & $88 \%$ & $67 \%$ \\
\hline XP 014713133 Donkey [Equus asinus] & $84 \%$ & $66 \%$ & $98 \%$ & $100 \%$ & $87 \%$ & $66 \%$ \\
\hline XP_006212709Alpaca [Vicuena pacos] & $8 \times 5$ & $66 \%$ & $88 \%$ & $84 *$ & $100 \%$ & 675 \\
\hline XP 416822 Chicken [Gallus pallas] & $66 \%$ & $83 \%$ & $67 \%$ & $64 \%$ & $67 \%$ & $100 \%$ \\
\hline XP 019467554 Turkey (Meleagris gallopano] & 565 & $65 \%$ & $36 \%$ & 545 & $55 * 6$ & 725: \\
\hline XP 010833001/American bison [Biscen bisese bisoes] & $98 \%$ & $67 \%$ & $86 \%$ & 796 & $89 \%$ & $68 \%$ \\
\hline XP_020768969:Teras whitertail deer [Odocoileus virginianus texanus] & $92 \%$ & $66 \%$ & $82 \%$ & $78 \%$ & $85 \%$ & $67 \%$ \\
\hline XP 031451919 Conemson pheasant [Plasianus colchices] & $60 \%$ & $84 \%$ & $67 \%$ & $64 \%$ & $67 \%$ & $96 \%$ \\
\hline XP 007090142 Tiger [Panthers tigris altaica] & $83 \%$ & $66 \%$ & $88 \div$ & s5s & $85 \%$ & $68 \%$ \\
\hline XP 032963186.1 Herseshes bas [Rhinolophus femumsquinum] & 800 & $64 \%$ & $86 \%$ & 825 & $82 \%$ & 652 \\
\hline $2 c$ & Turkey & Bson & Deer & Pheasant : & Tirter: & $\begin{array}{l}\text { Morseshoe } \\
\text { bat }\end{array}$ \\
\hline NP. 001358344Human [Homs xapicme] & 5906 & $43 \%$ & $66 \%$ & $66 \%$ & $85 \%$ & $81 \%$ \\
\hline XP 005228485 Cattle [Bos tannis] & $59 \%$ & 535 & $77 \%$ & $65 \%$ & $78 \times$ & $76 \%$ \\
\hline XP 027389727Hybrid catle X1 [Bos indicus $x$ Bos taurus] & $59 \%$ & $53 \% 6$ & $77 \% 6$ & $64 \%$ & 7626 & $76 \%$ \\
\hline XP 027389729Hybrid cattle X2 [Bos indicus $x$ Bos tuarus] & $59 \%$ & $54 \%$ & $78 \%$ & $66 \%$ & $82 \%$ & $80 \%$ \\
\hline NP_001116542 Pig [Sus scrofa] & 5906 & $48 \%$ & $72 \%$ & $66 \%$ & $83 \%$ & $80 \%$ \\
\hline XP 011961657 Dometic sheep [Ovis ancs] & $60 \%$ & $52 \%$ & $78 \%$ & $67 \%$ & $82 \%$ & 800 \\
\hline NP 001277036 Domestic gout [Capa hircui] & $5 \sin 6$ & $53 \%$ & $78 \%$ & 675 & $82 \%$ & $80 \%$ \\
\hline XP 025976569 Emu [Dromais sevachollandiae] & 696 & $36 \%$ & $55 \%$ & $84 \%$ & $\cos$ & $65 \%$ \\
\hline XP 0014902411 Horse [Egew caballus]. & $\cos$ & $46 \%$ & $60 \%$ & $67 \%$ & $87 \%$ & $86 \%$ \\
\hline XP 014713133 Donkey [Equas asinus] & $50 \%$ & $43 \%$ & $68 \div 6$ & $67 \%$ & $86 \%$ & $84 \div$ \\
\hline XP_0062127094lpuca [Vicuena pacos] & $59 \%$ & $47 \%$ & $72 \%$ & $67 \%$ & $84 \%$ & 825 \\
\hline XP 416822 Chicken [Galliar gallus] & $77 \%$ & $36 \%$ & $56 \%$ & $96 \%$ & $67 \%$ & $65 \%$ \\
\hline XP. 019467554 Turkey [Meleagris pallogavo] & 1000 & $34 *$ & $49 \%$ & $74 \%$ & $56 \%$ & $54 \%$ \\
\hline XP 010833001 Amcrican bison [Bison bison bison] & $67 \%$ & $100 \%$ & $97 \%$ & $67 \%$ & $81 \%$ & $80 \%$ \\
\hline XP_020768965T Tevas whiletail dect [Odecoilews virginianus texans] & $62 \%$ & 624 & $100 \%$ & $67 \% 6$ & $79 \%$ & $76 \%$ \\
\hline 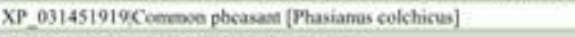 & $79 \%$ & $36 \%$ & $56 \%$ & 1005 & $67 \%$ & $65 \%$ \\
\hline XP 007090142Tizer [Panthera tigris altaica] & $61 \%$ & $44 \% 6$ & $67 \%$ & $68 \%$ & $100 \%$ & $83 \%$ \\
\hline XP 032963186.1 Hosseshoc bat [Rhinolophus femumequinum] & $58 \%$ & $43 \%$ & $64 \%$ & $66 \%$ & $82 \%$ & $100 \%$ \\
\hline
\end{tabular}


Appendix 3. Distance matrix table using only the 20 known SARS-CoV-2/ACEII interaction sites (3a: humans, cattle, hybrid cattle, pigs, and sheep; 3b: goat, emu, horse, donkey, alpaca, and chicken; 3c: turkey, bison, deer, pheasant, tiger, and bat).

\begin{tabular}{|c|c|c|c|c|c|c|}
\hline $2 a$ & & & Hybrid cattic & Hybrid cattle & & \\
\hline SQ. & Human: & Cattle & $\mathbf{x 1}$ & $x 2$ & Pis. & Sheep \\
\hline NP 001358344 Human [Homo sapiens] & $100 \%$ & $85 \%$ & $85 \%$ & $85 \%$ & $85 \%$ & $85 \%$ \\
\hline XP 005228485 Cattle [Bos taurus] & $85 \%$ & $100 x$ & $100 \%$ & $100 \%$ & $100 \%$ & $100 \%$ \\
\hline XP 027389727] Hybrid cattle XI [Bos indicus $x$ Bos taurus] & $85 \%$ & $100 \%$ & $100 \%$ & $100 \%$ & $100 \%$ & $100 \%$ \\
\hline XP 027389729 Hybrid cattle X2 [Bos indicus $x$ Bos taurus] & $85 \%$ & $100 \%$ & $100 \%$ & $100 \%$ & $100 \%$ & $100 \%$ \\
\hline NP 001116542 Pig [Sus scrofa] & $80 \%$ & $85 \%$ & $85 \%$ & $85 \%$ & $85 \%$ & $85 \%$ \\
\hline XP 011961657] Domestic shecp [Ovis aries] & $85 \%$ & $100 \%$ & $100 \%$ & $100 \%$ & $100 \%$ & $100 \%$ \\
\hline NP 001277036) Domsstic goat [Capra hircus] & $85 \%$ & $95 \%$ & $95 \%$ & $95 \%$ & $95 \%$ & $95 \%$ \\
\hline XP 025976569 Emu [Dromaius novachollandiac] & $53 \%$ & $53 \%$ & $53 \%$ & $53 \%$ & $53 \%$ & $53 \%$ \\
\hline XP 001490241]Horse [Equus caballus] & $80 \%$ & $75 \%$ & $75 \%$ & $75 \%$ & $75 \%$ & $75 \%$ \\
\hline XP 014713133 Donkey [Equus asinus] & $80 \%$ & $75 \%$ & $75 \%$ & $75 \%$ & $75 \%$ & $75 \%$ \\
\hline XP 006212709/Alpaca [Vicugna pacos] & $75 \%$ & $80 \%$ & $80 \%$ & $80 \%$ & $80 \%$ & $80 \%$ \\
\hline XP 416822 Chicken [Gallus gallus] & $58 \%$ & $58 \%$ & $58 \%$ & $58 \%$ & $58 \%$ & $58 \%$ \\
\hline XP 019467554Turkey [Meleagris gallopavo] & $58 \%$ & $58 \%$ & $58 \%$ & $58 \%$ & $58 \%$ & $58 \%$ \\
\hline XP 010833001/American bison [Bison bison bisoa] & $85 \%$ & $100 \%$ & $100 \%$ & $100 \%$ & $100 \%$ & $100 \%$ \\
\hline XP 020768965]Texas whitetail deer [Odocoileus virginianus texanus] & $85 \%$ & $100 \%$ & $100 \%$ & $100 \%$ & 1000 & $100 \%$ \\
\hline XP 031451919 Common pheasant [Phasianus colchicus] & $58 \%$ & $58 \%$ & $58 \%$ & $58 \%$ & $58 \%$ & $58 \%$ \\
\hline XP_007090142Tiger [Panthera tigris altaica] & $85 \%$ & $80 \%$ & $80 \%$ & $80 \%$ & $80 \%$ & $80 \%$ \\
\hline XP 032963186.1 Horseshoe bat [Rhinolophus fernumequinum] & 5s\% & $50 \%$ & $50 \%$ & SOH & SOH & $50 \%$ \\
\hline 310 & Goat & Emu. & Horse: & Donkey & Alpaci & Chicken \\
\hline NP 001358344 Human [Homo sapicns] & $85 \%$ & $85 \%$ & $80 \%$ & $80 \%$ & $80 \%$ & $75 \%$ \\
\hline XP 005228485 Cattle [Bos taurus] & $95 \%$ & $100 \%$ & $85 \%$ & $75 \%$ & $75 \%$ & $80 \%$ \\
\hline XP 027389727 Hybrid cattle X1 [Bos indicus $x$ Bos tauns] & $95 \%$ & $100 \%$ & $85 \%$ & $75 \%$ & $75 \%$ & $80 \%$ \\
\hline XP_027389729 Hybrid cattle X2 [Bos indicus $x$ Bos taunts] & $95 \%$ & $100 \%$ & $85 \%$ & $75 \%$ & $75 \%$ & $80 \%$ \\
\hline NP 001116542 Pig [Sus scrofa] & $90 \%$ & $85 \%$ & $100 \%$ & $80 \%$ & $80 \%$ & $80 \%$ \\
\hline XP 011961657 Domestic sheep [Ovis aries] & $95 \%$ & $100 \%$ & $85 \%$ & $75 \%$ & $75 \%$ & $80 \%$ \\
\hline NP 001277036 Domestic goat [Capra hircus] & $100 \%$ & $95 \%$ & $90 \%$ & $75 \%$ & $75 \%$ & $75 \%$ \\
\hline XP 025976569 Ema [Dromaius novachollandiac] & $58 \%$ & $53 \%$ & $58 \%$ & $42 \%$ & $42 \%$ & $58 \%$ \\
\hline XP 001490241] Horse [Equus caballus] & $75 \%$ & $75 \%$ & $80 \%$ & $100 \%$ & $100 \%$ & $70 \%$ \\
\hline XP 014713133 Donkey [Equus asinus] & $75 \%$ & $75 \%$ & $80 \%$ & $100 \%$ & $100 \%$ & $70 \%$ \\
\hline XP 006212709/Alpoca [Vicugna pacos] & $75 \%$ & $80 \%$ & $80 \%$ & $70 x$ & $70 \%$ & $100 \%$ \\
\hline XP 416822 Chicken [Gallus gallus] & $58 \%$ & $58 \%$ & $58 \%$ & $47 \%$ & $47 \%$ & $63 \%$ \\
\hline XP_019467554/Turkey [Meleagris gallopavo] & $58 \%$ & $58 \%$ & $58 \%$ & $47 \%$ & $47 \%$ & $63 \%$ \\
\hline XP 010833001 American bison [Bison bison bison] & $95 \%$ & $100 \%$ & $85 \%$ & $75 \%$ & $75 \%$ & $80 \%$ \\
\hline XP 020768965 Texas whitetail decr [Odocoileus virginianus texanus] & $95 \%$ & $100 \%$ & $85 \%$ & $75 \%$ & $75 \%$ & $80 \%$ \\
\hline XP 031451919 Common phcasant [Phasianus colchicus] & $58 \%$ & $58 \%$ & $58 \%$ & $47 \%$ & $47 \%$ & $63 \%$ \\
\hline XP_007090142/Tiger [Panthera tigris altaica] & $80 \%$ & $80 \%$ & $85 \%$ & $95 \%$ & $95 \%$ & $75 \%$ \\
\hline XP 032963186.1 Horseshoe bat [Rhinolophus ferrumequinum] & $55 \%$ & $50 \%$ & $60 \%$ & $65 \%$ & $65 \%$ & $55 \%$ \\
\hline 36 & Turkey. & Bison & Deer & Pheasant & Tiger & $\begin{array}{l}\text { Forseshoe } \\
\text { bat }\end{array}$ \\
\hline NP 001358344Human [Homo sapicns] & SSK & $55 \%$ & $55 \%$ & $50 \%$ & $85 \times$ & $55 \%$ \\
\hline XP 005228485 Cattle [Bos taurus] & $55 \%$ & $55 \%$ & $55 \%$ & $50 \%$ & $80 \%$ & $50 \%$ \\
\hline XP 027389727]Hybrid cattle X1 [Bos indicus $\mathrm{x}$ Bos taunus] & $55 \%$ & $55 \%$ & $55 \%$ & $50 \%$ & $80 \%$ & $50 \%$ \\
\hline XP_027389729Hybrid cattle X2 [Bos indicus x Bos taurus] & S5\% & $55 \%$ & SS\% & sox & $80 \%$ & sox \\
\hline NP 001116542/Pig [Sus scrofa] & $55 \%$ & $55 \%$ & $55 \%$ & $55 \%$ & $85 \%$ & $60 \%$ \\
\hline XP 011961657]Domestic sheep [Ovis aries] & $55 \%$ & $55 \%$ & $55 \%$ & $50 \%$ & $80 \%$ & $50 \%$ \\
\hline NP 001277036] Doasestic goat [Capra hircus] & S5X & 55\% & $5 S \%$ & S5\% & $80 \%$ & $55 \%$ \\
\hline XP 025976569 Emu [Dromaius novachollandiac] & $79 \%$ & $74 \%$ & $74 \%$ & $100 \%$ & $47 \%$ & $63 \%$ \\
\hline XP 001490241|Horse [Equus caballus] & $45 \%$ & $45 \%$ & $45 \%$ & $40 \%$ & $95 \%$ & $65 \%$ \\
\hline XP 014713133 Donkey [Equus asinus] & $45 \%$ & $45 \%$ & $45 \%$ & $40 \%$ & $95 \%$ & $65 \%$ \\
\hline XP_006212709[Alpaca [Vicugna pacos] & $60 x$ & $60 \%$ & $60 \%$ & $55 \%$. & $75 \%$ & $55 \%$ \\
\hline XP 416822/Chicken [Gallus gallus] & $100 \%$ & $95 \%$ & $95 \%$ & $79 \%$ & $53 \%$ & $53 \%$ \\
\hline XP_019467554Turkey [Meleagris gallopavo] & $95 \%$ & $100 \%$ & $100 \%$ & $74 \%$ & $53 \%$ & $47 \%$ \\
\hline XP $010833001 /$ Amsrican bison [Bison bison bison] & $55 \%$ & $55 \%$ & $55 \%$ & sos & $80 \%$ & $50 \%$ \\
\hline XP 020768965 Texas whitetail deer [Odocoileus virginianus texanus] & S5\% & $55 \%$ & $55 \%$ & sox & $80 \%$ & $50 \%$ \\
\hline XP 031451919 Common pheasant [Phasianus colchicus] & $95 \%$ & $100 \%$ & $100 \%$ & $74 \%$ & $53 \%$ & $47 \%$ \\
\hline XP_007090142/Tiger [Panthera tigris altaica] & $50 \%$ & $50 \%$ & $50 \%$ & $45 \%$ & $100 \%$ & $60 \%$ \\
\hline XP 032963186.11 Horseshoe bat [Rhinolophus ferrumequinum] & $50 \%$ & $45 \%$ & $45 \%$ & $60 \%$ & $60 \%$ & $100 \%$ \\
\hline
\end{tabular}

